Review Article

\title{
Analysis of COVID -19: Where Do We Stand?
}

\author{
Cornelli Umberto, ${ }^{1 *}$ Belcaro Giovanni, ${ }^{2}$ Cesarone Maria Rosaria, ${ }^{2}$ Recchia Martin, ${ }^{3}$ Cotellese Roberto ${ }^{4}$ \\ ${ }^{1}$ Higher Technical Institute for life Technologies, Bergamo, Italy \\ ${ }^{2}$ IRVINE 3 labs and OOLEX C-virus University G.d'Annunzio -Pescara-Chieti, Italy \\ ${ }^{3}$ University of Lugano-Switzerland, Italy \\ ${ }^{4}$ University G. d’Annunzio Pescara-Chieti-Italy
}

\begin{abstract}
Background: The COVID-19 is a real pandemia and only very few countries in the world were minimally affected.

Objective: To measure the impact of COVID-19 deaths in 49 countries ( 49 SC or selected countries) and correlate them with, ecological, demographical, social, economic variables, aging and chronic diseases.

Material and methods: The 49 SCs are those considered by WHO reliable in term of deaths records.

Data concerning COVID-19 were taken from John Hopkins records updated to December $5^{\text {th }}$. The ecological, demographical, social, economical variable were consistent with the CIA Fact Book 2020. The deaths due to the most common diseases and cancers were taken from the WHO records in term of ASDRs (Age Standardized Death Rate). The age index was taken from The World Bank. The correlations were calculate in term "r" (linear correlation).
\end{abstract}

Results: The 49 SC represent about $19 \%$ of the world population accounting for about $61 \%$ of the total worldwide deaths. Very consistent differences among countries were shown, from $0 \%$ deaths up to $1.5 \%$ deaths $/ 1000$ inhabitants. Any correlation was found with aging and ecological, demographical/social, economic variables. The same was for the most common diseases (a part of peptic ulcer) and cancers (a part of bladder cancer).

Conclusion: The COVID-19 seems to be an independent disease, and the efficiency in reducing deaths belongs mainly by political issues.

Keywords: COVID-19, Aging, Ecology, Demography, Economy, Chronic diseases, Cancers

\section{Introduction}

The COVID-19 pandemia at December $5^{\text {th }}$ was affecting about 66 million of people around the world and caused $>1.5$ million of deaths in a percentage of $0.23 \%$ of the cases. There are very consistent differences among countries, but the number of positive cases belongs to the number of swabs taken which contains some bias due to the repeated tests and false negative tests. The number of deaths seems to be a more solid variable, despite the issue about deaths for or with COVID-19. However, a very strong correlation has been calculated between number of swabs, positive cases and deaths. $^{1}$

\section{The numbers of COVID-19 deaths in the 49 SC}

We based our analysis on deaths, considering only those 49 SC (Selected Countries) out of the total of 191 countries, namely those considered by WHO reliable in terms of death records, ${ }^{2}$ which represent only about the $20 \%$ of the world population. These 49 SC, in terms of death were arbitrarily divided into 5 categories from those at "very high mortality" down to "no mortality" as represented in Table 1, which reports also the countries which has been considered. Summing up all the deaths up to December $5^{\text {th }, 3}$ these countries represent the $61.2 \%$ of the total deaths with rates going
Quick Response Code:

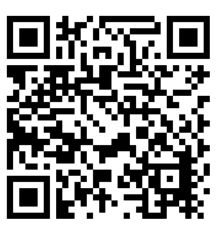

*Corresponding author: Umberto Cornelli, Higher Technical Institute for life Technologies, Bergamo, Piazza Novelli 520129 Milan, Italy

Received: 14 December, 2020

Published: 24 February, 2021

Citation: Cornelli U, Belcaro G, Cesarone MR, Recchia M, Cotellese R. Analysis of COVID -19: Where Do We Stand?. Pregn Womens Health Care Int J. 2021;1(1):1-4. DOI: 10.53902/PWHCIJ.2021.01.000504 
from 1.5 deaths $/ 1000$ positive cases down to $0 / 1000$ positive cases. The first element analyzed was the geography. Apparently, there are no evident connections between the severity of the disease and the geographical location of the countries. The season seems not to

Table 1: Percentage of deaths due to COVID-19 in the 49 SC: measures in terms of death/1000 inhabitants.

\begin{tabular}{|c|c|c|}
\hline Percentage & Measure Case $/ 10^{3}$ Inhabitants & Country $^{\mathrm{a}}$ \\
\hline The highest & 1.5 & Belgium \\
\hline Very high & 0.8 to 1.0 & Spain, UK, Mexico, Macedonia, USA, Chile, Brazil, France, Czekia, Slovenia \\
\hline High & 0.6 to 0.8 & Armenia, Sweden, Switzerland, Luxembourg, Romania \\
\hline Medium & 0.4 to 0.6 & Italy, Moldova, Netherland, Hungary, Croatia, Ireland, Bahamas, Austria \\
\hline Low & 0.2 to 0.4 & Canada, Malta, Guatemala, Germany, Kyrgyzstan, Lithuania \\
\hline Very low & 0.02 to 0.2 & $\begin{array}{c}\text { Slovakia, Denmark, Latvia, Estonia, Trinidad \&Tobago, Iceland, Finland,Norway, Australia, } \\
\text { Uzbekistan }\end{array}$ \\
\hline Minimal & 0.01 to 0.2 & Japan, Cuba, South Korea, Mauritius, Brunei, New Zealand \\
\hline None & 0 & Grenada, Saint Vincent \& Grenadinas \\
\hline
\end{tabular}

$a=$ In the same raw the countries are listed in order of deaths/1000 inhabitants (e.g. Spain $>$ UK> Mexico).

The ecological, demographical, social, and economical aspects

When these elements such were considered ${ }^{4,5}$ any significant correlation was found (Table 2).

Table 2: Correlations between some of the most documented ecological, demographical, social, and economical characteristic of the $49 \mathrm{SC}$ and COVID-19 deaths.

\begin{tabular}{|c|c|}
\hline Characteristic & Significant $^{\mathbf{a}}$ \\
\hline Population density & No \\
\hline GPD/inhabitant & No \\
\hline Instruction $^{\text {}}$ & No \\
\hline Hospitals & No \\
\hline Forest $\%$ in the territory & No \\
\hline Cars/1000inhabitant & No \\
\hline Cell phone/1000 inhabitants & No \\
\hline Internet $/ 1000$ inhabitants & No \\
\hline PM (particular Matter) & No \\
\hline
\end{tabular}

a: Linear correlation coefficient; Cut-of for the statistical significance = 0.288;b: GDP (Gross Domestic Product)

\section{Any correlation was found in the 49 SC}

However, it is possible that for some countries few correlations can be present. It has been shown (Italy) that the most prosperous Regions, characterized by more facilities (and workers) were significantly more affected, and people living on the hills were less affected compared to those living on flat land and mountains. Similarly correlations with GDP were found. ${ }^{1}$ It was happening that over the time, some correlations that were present in the early phases, were disappearing, meaning that the increase of deaths is flattening the differences among countries. ${ }^{6,7}$ At the end, it seems that each country should be considered per se.

\section{The problem of aging}

One of the main issues to be considered was the age. Aging indexes were taken from the data of the World Bank. ${ }^{8}$ It has been de- have an impact on the disease. However, in some of the countries where the seasonal gradients of temperature are usually large, the infection was more consistent with the cold weather. scribed that elderly people can be more sensible to the COVID-19 and to the relative death.

The present analysis was conducted considering one of the most common index of aging represented by the ratio people $>65$ year/25 years. No correlation was found, which means that aging is not the real problem when deaths are considered as numbers $/ 1000$ people. Since the appearance of humans in the globe, death is bound to aging. Now days in most of the countries the chance of dying is about 20 times higher after the age of 65 years when compared to the age of the rest of the population. In relation to COVID-19 one may not rule out the rumors that once very old people are getting into the ICU (Intensive Care Units) their chance of survive is very low. Sometimes politicians make inappropriate comments, such that we may expect our grandfathers will dye due to COVID-19 because they have lived enough and become a burden for the society. It may happen during the acute emergency for COVID-19, when the ICUs were insufficient to take care of all the severe cases, doctors had to take a hard decision about who should be addressed with more attention. The real solution should be to increase the ICUs, or to improve the assistance at home and in the nursing home. However, in many countries even in those most advanced this was not done properly and the local politicians are principally responsible for this inattention.

\section{The problem of concomitant diseases}

The other important aspect to be focused was the problem of concomitant diseases. It is obvious that people with chronic diseases could be more sensible to the viral aggression. In the present analysis was calculated the correlation between deaths due to COVID-19 and those for chronic diseases, and no correlation was shown in the 49 SC (Table 3). The chronic diseases were consistent with the ASDRs (Age Standardized Death rates) taken by the WHO records of 2016. ${ }^{2}$ The ASDR is a mirror of a disease dimension in the country, since the higher the value the higher is the number of cases affect by the given disease. Data for 2020 were not available but it is known that ASDRs are highly correlated during time, therefore the 
data of 2016 represent a condition significantly similar to $2020 .^{7}$ Any correlation was found, a part of peptic ulcer with a negative value. Obesity was not considered because there were no data on the WHO records in terms of ASDRs.

Table 3: Correlations between COVID-19 deaths and chronic diseases: data based on the ASDRs.

\begin{tabular}{|c|c|}
\hline Disease & Significant $^{\mathbf{a}}$ \\
\hline Diabetes & NO \\
\hline Iron-deficiency anemia & NO \\
\hline Tuberculosis & NO \\
\hline STD (sexually transmitted disease) & NO \\
\hline HIV/AIDS & NO \\
\hline Diarrheal diseases & NO \\
\hline Hepatitis & Negative \\
\hline Peptic ulcer & NO \\
\hline Respiratory diseases & NO \\
\hline Alzheimer & NO \\
\hline CVDs & NO \\
\hline Ischemic stroke & NO \\
\hline Hemorrhagic stroke & NO \\
\hline Respiratory diseases & NO \\
\hline Digestive diseases & NO \\
\hline Chronic kidney disease & \\
\hline
\end{tabular}

a: Linear correlation coefficient; Cut-of for the statistical significance $=$ 0.288 .

The event that people affected by peptic ulcer seem to be protected from the COVID-19 death has to be clarified. The hypothesis is that peptic ulcer is due mostly to the chronic presence of Helicobacter pilory which can be a trigger for the immunity against the COVID-19. In relation to cancers, no correlation was found for breast cancer, ovarian cancer, and for all the other most common cancers a part of bladder cancer $(r=0.3845 \mathrm{p}<0,05)$. Despite papilloma and HIV virus were supposed to be involved in this type of cancer, the available data in the literature are not considered consistent with this hypothesis. In the end, the relationship between bladder cancer and viral infections remain obscure.

\section{Where the virus come from}

In relation to the origin of COVID-19, the most documented hypothesis is the viral transfer from animals. The bats, particularly those endemic in China, where considered as the primary source. However, once the transfer animal/humans takes place, the main element of diffusion is the viral charge, such that an excessive viral concentration will be the real trigger for the human/human spreading. There is a documented hypothesis that the viral infection in humans started in China and was spread around the world. ${ }^{9}$ The spreading capacity of this virus is extremely high and its clinical expression fortunately is very low. The viral concentrations up to a certain limit may be counteracted by the natural defenses which can create an appropriate resistance. This is the case of the so called asymptomatic subjects who may become vectors of the virus.
It may happen that a particular genetic predispositions belonging to the ethnicity, country environment, and/or eating habits can limit the clinical expression of the virus. This was happening historically for many infections that were brought from one continent to the other (e.g. measles or syphilis), and can be the case of COVID-19 also. This aspect may justify why deaths in some countries are so limited, while in other are so high. It is known in that the virus concentrate in the salivary gland $\mathrm{s}^{10}$ and droplets of saliva become the main vectors. Humans produce about $1.5 \mathrm{~L}$ of saliva/day, more or less like the urine excretion. Therefore, the oral hygiene should be addressed very carefully, together with the masks, hands disinfection, and the distance among humans. It seems that virologists and epidemiologists have forgotten that the oral hygiene is extremely important, and nobody never mentions this aspect during the media interviews and debates. However, one may expect that this virus will become part of the meta-organism of many humans, and its clinical evidence will come out periodically, like measles, herpes virus or HIV.

\section{Can the virus diffuse trough the water? The temperature generated by the water can influence the viral growth?}

The high temperature $>40^{\circ} \mathrm{C}$ may reduce the viral contamination, ${ }^{11}$ which is not the case of water in rivers, lakes or domestic. At the opposite low temperature can maintain the virus alive. During spring or summer the water rarely exceeds $25-26^{\circ} \mathrm{C}$, while during winter the temperature can be lower than $4^{\circ} \mathrm{C}$. In other terms, water can be an ideal environment to maintain the virus alive. One possible explanation can be drawn from the viral structure. The COVID-19 structure consists of 4 main sets of proteins: S (spyke), $\mathrm{N}$ (nucleocapsid), M (membrane, and E (envelop). The S mediates the viral cell-cell fusion with adjacent non infected cell, forming giant syncitia which allow the viral spreading. The E protein, despite being the smallest of the group, is important for viral spreading, because its loss determine the reduction of the viral titres. ${ }^{12}$ The $\mathrm{E}$ protein is hydrophobic, and can protect the virus from the water. A consistent increase of temperature can modify this protein making it less effective, but this not the case of the water at the common temperature, no matter if domestic or pertaining to rivers/lakes. The dimension of COVID-19 is between $100-150 \mathrm{~nm}$, and masks with a filter of $30 \mathrm{~nm}$ are efficient to stop the air contamination, while the filtering devices used for domestic water can stop particles higher than $200 \mathrm{~nm}$, and the in case of COVID-19 are totally useless. An efficient water purification system usually eliminate any viral charge either for filtration and by physico/chemical treatment (e.g. UV, chloride, NaClO). However, contamination can take place once the water gets into the pipelines of the territories and houses. However, more water means also more evaporation which may spread the infected particles around. Because of this, one may not rule out a direct/indirect effect of water, and this aspect needs appropriate studies and controls.

\section{Tentative Therapy}

In every country the infection was faced using different approaches, and therapies based upon antiviral (e.g. favipinavirr, 
remdesivir, lopinavir), antimalaric (e.g. chloroquine, hydroxychloroquine), traditional medicine (e.g. Indian, Chinese), passive antibody therapy with convalescent sera, or monoclonal antibodies. Up to now, all these therapies were merely a tentative and the results of many clinical trials were disappointing. In a survey done in the Italy ${ }^{13}$ it was shown that the flu vaccination, which are known to stimulate the immunity, was protecting from COVID-19. Now days there is a strong believe on specific vaccinations, and in few months several vaccines will be available. However, the real impact of any vaccine on the viral spreading is not known for the moment, because it has to be determined if subjects after the vaccination can still spread the virus. Hopefully not. Furthermore, the measure of the possible side effects of any vaccine has to be measured properly, and in case of million of people treated one may expect that they will come out in some cases, addressing the issue of the risk benefit ratio. The problem of viral drifts is also emerging making more difficult the evaluation of the vaccines efficency.

\section{Conclusion}

Covid-19 is having an impact in the world that can be compared to a war, that nobody would like to suffer and everybody can be a victim. Each country may have a different picture, but the common shield will be the appropriate information and health care assistance, which should be spread out in the same way of the virus. This is mainly matter of politics, which is discovering its inefficiency with crude numbers.

\section{Ethical statement}

The manuscript is original, has not been published before and is not being considered for publication elsewhere. All the authors mentioned in the manuscript have agreed on the authorship, read and approved the manuscript, and given consent for submission and subsequent publication for the manuscript. The data file was enclosed as a separate document, and can be used only upon request to the authors.

\section{Acknowledgments}

We need to give our condolences to the families of COVID-19 victims, and our proximity to the people suffering from this viral infection. We are also grateful to the medical personnel of all the countries and to the volunteers who were professionally and emotionally dedicated to the patients affected by the disease. UC conceived the trial; UC, GB, MRC, RC were collecting the data; MR was in charge to make the statistical evaluation, UC wrote the text.

\section{Conflicts of Interest}

No conflict of interest.

\section{Financial Support}

No financial support.

\section{References}

1. Cornelli U, Belcaro G, Cesarone M Recchia M, et al. Cov 19 in Italy: correlation with clinical demographical, social variables, and water. JMCRR. 2020;4(6):1-10.

2. Global Health Estimates 2016: death by Cause, Age, Sex, by Country and by Region 2000-2016 Geneva World Health Organization. 2018.

3. COVID-19 Map-Global Map Coronavirus Resource Center. 2020.

4. The CIA World Factbook 2020 May 21 Ed Skyhorse Publishing.

5. Atlante Geografico DE Agostini 2016 Ed De Agostini Novara Italy.

6. Cornelli U, Belcaro G, Cesarone MR, et al. Coronavirus Cov19: the status in Italy taken as an example of the virus spreading in the world. $J$ Med Clin Res Rev. 2020;4(5):1-9.

7. Cornelli U, Belcaro G, Cesarone MR, et al. Coronavirus Cov19 aging and chronic diseases. Microb Infect Dis. 2020;4(4):1-6.

8. The World Bank.

9. Cornelli U, Belcaro G, Cesarone MR, et al. The COVID.19 Infection in Lombardia come from China. Microb Infect Dis. 2020; 4(4):1-4.

10. Belcaro G, Cornelli U, Cesarone MR, et al. Virucidals control the presence of Covid in mouth/saliva. Med Clin Res. 2020:5(5).

11. Belcaro G, Cornelli U, Cesarone MR et al. Seven immediate, low-cost management strategies for Covid. Exploiting viral thermolability: possible, immediate solutions. BJSTR 2020 MS. ID. 0044506.

12. Schoeman D, Fielding BC. Coronavirus envelope: current knowledge. Virology J. 2019;16:69.

13. Cornelli U, Belcaro G, Cesarone MR, et al. The COVID-19 history in Italy: correlation s with environmental, demographic variables and chronic diseases. JMCRR. 2020;4(10):1-13. 